\title{
BMJ Open Costs of switching to low global warming potential inhalers. An economic and carbon footprint analysis of NHS prescription data in England
}

\author{
Alexander J K Wilkinson (D) , ${ }^{1}$ Rory Braggins, ${ }^{2}$ Ingeborg Steinbach, ${ }^{3}$ James Smith ${ }^{2}$
}

To cite: Wilkinson AJK, Braggins R, Steinbach I, et al. Costs of switching to low global warming potential inhalers. An economic and carbon footprint analysis of NHS prescription data in England. BMJ Open 2019;9:e028763. doi:10.1136/ bmjopen-2018-028763

- Prepublication history for this paper is available online. To view these files, please visit the journal online (http://dx.doi. org/10.1136/bmjopen-2018028763).

Received 30 January 2019 Revised 17 September 2019 Accepted 18 September 2019

Check for updates

(C) Author(s) (or their employer(s)) 2019. Re-use permitted under CC BY-NC. No commercial re-use. See rights and permissions. Published by BMJ.

${ }^{1}$ Respiratory Department, East and North Hertfordshire NHS Trust, Stevenage, UK ${ }^{2}$ Department of Public Health and Primary Care, School of Clinical Medicine, University of Cambridge, Cambridge, UK

${ }^{3}$ Centre for Sustainable Healthcare, Oxford, UK

Correspondence to Dr Alexander J K Wilkinson; alex.wilkinson2@nhs.net

\section{ABSTRACT}

Objectives Metered-dose inhalers (MDIs) contain propellants which are potent greenhouse gases. Many agencies propose a switch to alternative, low global warming potential (GWP) inhalers, such as dry powder inhalers (DPIs). We aimed to analyse the impact on greenhouse gas emissions and drug costs of making this switch.

Setting We studied National Health Service prescription data from England in 2017 and collated carbon footprint data on inhalers commonly used in England.

Design Inhalers were separated into different categories according to their mechanisms of action (eg, short-acting beta-agonist). Within each category we identified low and high GWP inhalers and calculated the cost and carbon impact of changing to low GWP inhalers. We modelled scenarios for swapping proportionally according to the current market share of each equivalent DPI (model 1) and switching to the lowest cost pharmaceutically equivalent DPI (model 2). We also reviewed available data on the carbon footprint of inhalers from scientific publications, independently certified reports and patents to provide more accurate carbon footprint information on different types of inhalers.

Results If MDls using HFA propellant are replaced with the cheapest equivalent $\mathrm{DPI}$, then for every $10 \%$ of MDIs changed to DPIs, drug costs decrease by £8.2M annually. However if the brands of DPIs stay the same as 2017 prescribing patterns, for every $10 \%$ of MDls changed to DPIs, drug costs increase by £12.7M annually. Most potential savings are due to less expensive long-acting beta-agonist (LABA)/inhaled corticosteroids (ICS) inhalers. Some reliever inhalers (eg, Ventolin) have a carbon footprint over $25 \mathrm{~kg} \mathrm{CO}$ e per inhaler, while others use far less 1,1,1,2-tetrafluoroethane (HFA134a) (eg, Salamol) with a carbon footprint of $<10 \mathrm{~kg} \mathrm{CO}$ e per inhaler. 1,1,1,2,3,3, 3-Heptafluoropropane (HFA227ea) LABA/ICS inhalers (eg, Flutiform) have a carbon footprint over $36 \mathrm{~kg} \mathrm{CO}_{2} \mathrm{e}$, compared with an equivalent HFA134a combination inhaler (eg, Fostair) at $<20 \mathrm{~kg} \mathrm{CO} \mathrm{C}_{2}$ e. For every $10 \%$ of MDls changed to DPIs, 58 kt $\mathrm{CO}_{2}$ e could be saved annually in England.

Conclusions Switching to DPIs would result in large carbon savings and can be achieved alongside reduced drug costs by using less expensive brands. Substantial carbon savings can be made by using small volume HFA134a MDIs, in preference to large volume HFA134a MDIs, or those containing HFA227ea as a propellant.
Strengths and limitations of this study

This article draws together a variety of sources of information to demonstrate significant differences in the global warming potential of different inhalers.

- The National Health Service digital database provided a large, reliable dataset for us to analyse cost and greenhouse gas release in various scenarios.

- We calculated cost and greenhouse gas emissions for various scenarios in which inhalers are changed, and for different classes of inhalers (eg, inhaled steroids, beta-agonists).

- We were unable to analyse national prescription data by diagnosis and do not know which of the inhalers might have been used for asthma, chronic obstructive pulmonary disease or other diagnoses.

- Detailed information about the carbon footprint of all inhalers is not publicly available.

\section{INTRODUCTION}

Metered-dose inhalers (MDIs) contain propellants, which are liquefied, compressed gases used as a driving force and an energy source for atomisation of the drug. Chlorofluorocarbons (CFCs), which were used originally, are both potent greenhouse gases (GHGs) and ozone-depleting substances, and were banned under the Montreal Protocol. They have been replaced by two hydrofluoroalkane (HFA) propellants; 1,1,1,2-tetrafluoroethane (HFA134a) and 1,1,1,2,3,3,3-heptafluoro propane (HFA227ea). ${ }^{1}$ Currently, MDIs contribute an estimated $3.9 \%$ of the carbon footprint of the National Health Service (NHS) in the UK, because HFAs are potent GHGs. ${ }^{2}$ The UK has a high proportion of MDI use $(70 \%)$ compared with $<50 \%$ in the rest of Europe, and only about $10 \%$ in Scandinavia. ${ }^{3}$ The most commonly used MDIs in the UK contain salbutamol reliever, although there is pressure to reduce excessive reliever use, which has been linked with poor outcomes in asthma, in favour of controller therapies. ${ }^{4}$ 
Combating climate change has been described as 'the greatest public health opportunity of the 21st century'. HFAs are used mainly as refrigerants and are controlled under national F-gas regulations, and the Kigali Amendment to the Montreal Protocol. As F-gas use is phased out, HFA MDIs will become a significant proportion of overall HFA use, especially in the UK, because of the high level of use of MDIs.

There have been calls to switch away from HFA MDIs because of their environmental impact. ${ }^{6}$ Effective HFAfree alternatives are already available, as DPIs and aqueous mist inhalers. Switching to inhalers with lower global warming potential (GWP) is a key part of the NHS Sustainable Development Unit's strategy. ${ }^{7}$ In 2017, the British Thoracic Society recommended that prescribers and patients 'consider switching pMDIs to non-propellant devices whenever they are likely to be equally effective'. In May 2018, the UK's Environmental Audit Committee recommended the NHS set a target of reducing to $50 \%$ low GWP inhalers by 2022. ${ }^{9}$ In January 2019, the NHS long-term plan proposed a $50 \%$ reduction in the GHG emissions from inhalers in 10 years, ${ }^{10}$ and established an expert working group to evaluate potential strategies to achieve this. ${ }^{11}$ There is patchy information about the carbon footprint of inhalers. Life-cycle analysis of salbutamol MDIs has shown that $95 \%-98 \%$ of its carbon footprint derives from the use-phase, when the propellant is released and this dwarfs manufacturing processes. ${ }^{12-14}$ This article collates and analyses information on type and volume of emitted propellant.

A significant barrier to switching away from MDIs might be the higher 'up-front' price of some DPIs; however, the price of MDIs does not take into account the long-term financial cost of their environmental impact. We investigate a variety of scenarios for altered inhaler prescription patterns in England, and the cost implications of switching to MDIs.

\section{METHODS}

\section{Financial analysis}

We used 2017 prescription data from NHS digital website, including the number of inhalers prescribed and net ingredient cost. ${ }^{15}$ We separated inhalers into different categories: short-acting beta-agonists (SABAs), inhaled corticosteroids (ICS), long-acting beta-agonists (LABAs), short-acting muscarinic antagonists (SAMAs), longacting muscarinic antagonists (LAMAs) and combination devices. Within these categories, we identified high GWP inhalers which contain HFA propellant, and low GWP inhalers which were DPIs and Respimat devices. The least expensive low GWP inhaler in each inhaler category was identified, and the cost and carbon impact of changing inhalers determined in various scenarios. Some discontinued inhalers and those prescribed in very low numbers $(<500$ a year) were excluded from the analysis.

In model 1, we replaced MDIs with DPIs in the same proportions that brands of DPIs had been prescribed in
England 2017, which we called 'proportional replacement'. For example, if three DPI inhalers (A, B and C) made up $50 \%, 30 \%$ and $20 \%$ of the DPIs in that category, then proportional replacement would switch $50 \%$ of the MDIs to DPI inhaler A, $30 \%$ to B and $20 \%$ to C. The number of MDIs declines and DPIs increases, while the proportions of each DPI used stays the same.

In model 2, we replaced MDIs with the cheapest available equivalent DPI. We modelled several alternative scenarios described in table 1 and the paragraphs below on SABA and LABA/ICS combination inhalers.

SABA; salbutamol: in 2017, the least expensive MDI salbutamol was $£ 1.88$ versus the least expensive DPI salbutamol Salbulin Novolizer at $£ 3.36$ for 200-dose inhaler. However, the Salbulin Novolizer is rarely used in the UK, with only 1015 prescriptions in 2017, so we modelled an alternative scenario in which we changed MDIs to Salbutamol Easyhaler instead (£3.85 per inhaler).

$\angle A B A$ : the least expensive LABA in 2017 was Formoterol Easyhaler, which is similarly priced to the least expensive MDI LABA at £25.37 per inhaler.

ICS: we divided ICS inhalers as described in BTS/SIGN guidance into very low, low, medium and high strength inhalers. ${ }^{4}$ We identified the least expensive equivalent DPI ICS in each category. These were Flixotide $50 \mathrm{Accu}-$ haler (£8.54 per inhaler) one inhalation twice a day for very low strength, beclometasone 200 Easyhaler ( $£ 16.85$ per inhaler) one inhalation twice a day for low strength and two inhalations twice a day for medium strength, budesonide 400 Easyhaler (£20.39 per inhaler) two inhalations twice a day for high strength.

$L A B A / I C S$ combination inhalers: we divided inhalers into low, medium and high strength inhaled corticosteroids. The least expensive DPI inhalers were Seretide 100 Accuhaler (£23.89 per inhaler), Relvar 92/22 Ellipta (£25.31per inhaler) and Fostair 200/6 Nexthaler (£33.28 per inhaler), respectively. Relvar is a once-daily inhaler which would result in a change in dosing regimen for many patients, and it is also not licensed for maintenance and reliever therapy in patients with asthma. We therefore modelled an alternative scenario whereby we switched medium strength LABA/ICS combination inhalers to Fostair 100/6 Nexthaler (£33.42 per inhaler).

SAMA/LAMA and LAMA/LABA combination inhalers: we did not change these inhalers in our model as all SAMAs are MDI and all LAMAs and LAMA+LABA devices are DPI or aqueous mist inhalers. There are potential clinical and environmental benefits from switching SAMA to LAMA inhalers. ${ }^{16}$

LABA/LAMA/ICS inhalers: two of these 'triple' inhalers became available for the first time in 2017, one MDI (Trimbow at £47.42) and one DPI (Trelegy at £58.10 per inhaler).

\section{Greenhouse gas analysis}

Information on the amount of HFA propellant in MDIs is not publicly available, so alternative sources of information were sought. Studies have estimated the contents of 
Table 1 Financial implications of switching from MDls to DPls

\begin{tabular}{|c|c|c|c|c|c|}
\hline $\begin{array}{l}\text { Inhaler type (and most } \\
\text { common example) }\end{array}$ & $\begin{array}{l}\text { Number } \\
\text { prescribed } \\
\text { in } 2017\end{array}$ & $\begin{array}{l}\text { Total cost of this } \\
\text { type of inhaler (£) }\end{array}$ & $\begin{array}{l}\text { Cheapest DPI } \\
\text { alternative }\end{array}$ & $\begin{array}{l}\text { Cost }(£) \text { change } \\
\text { with proportional } \\
\text { replacement (per } \\
10 \%)\end{array}$ & $\begin{array}{l}\text { Cost }(£) \text { change } \\
\text { with cheapest } \\
\text { replacement (per } \\
10 \% \text { ) }\end{array}$ \\
\hline SABA (salbutamol MDI) & 21930625 & 58195683.24 & $\begin{array}{l}\text { Salbutamol } 100 \\
\text { Easyhaler }\end{array}$ & 3068201.99 & 3042770.28 \\
\hline LABA (salmeterol $25 \mathrm{MDI}$ ) & 700145 & 25250958.95 & $\begin{array}{l}\text { Formoterol } \\
\text { Easyhaler }\end{array}$ & 1474723.02 & -1018957.21 \\
\hline $\begin{array}{l}\text { Low dose ICS (Clenil } \\
\text { modulite 100) }\end{array}$ & 3874077 & 36581577.50 & $\begin{array}{l}\text { Beclometasone } \\
\text { Easyhaler 200, one } \\
\text { inhalation twice a } \\
\text { day }\end{array}$ & 2461791.16 & -213579.26 \\
\hline $\begin{array}{l}\text { High dose ICS (Clenil } \\
\text { modulite } 250)\end{array}$ & 287604 & 7923785.74 & $\begin{array}{l}\text { Budesonide } \\
\text { Easyhaler } 400 \text {, two } \\
\text { inhalations twice a } \\
\text { day }\end{array}$ & 1084787.73 & 173464.97 \\
\hline $\begin{array}{l}\text { Low dose ICS+LABA } \\
\text { (Seretide } 50 \text { Evohaler) }\end{array}$ & 1181941 & 32582876.16 & $\begin{array}{l}\text { Duoresp Spiromax } \\
160 / 4.5, \text { one } \\
\text { inhalation twice a } \\
\text { day }\end{array}$ & 749613.82 & 121485.45 \\
\hline $\begin{array}{l}\text { Medium dose ICS+LABA } \\
\text { (Fostair 100/6 MDI) }\end{array}$ & 9467562 & 373045012.90 & $\begin{array}{l}\text { Relvar Ellipta 92/, } \\
\text { one inhalation once } \\
\text { a day }\end{array}$ & 3124173.89 & -4876327.15 \\
\hline $\begin{array}{l}\text { ICS+LAMA+LABA } \\
\text { (Trimbow) }\end{array}$ & 5211 & 247464.50 & Trelegy Ellipta & 552801.25 & 552801.25 \\
\hline
\end{tabular}

DPI, dry powder inhaler; ICS, inhaled corticosteroid; LABA, long-acting beta-agonist; LAMA, long-acting muscarinic antagonist; MDI, metered-dose inhalers ; SABA, short-acting beta-agonist.

MDIs by weighing empty and full inhalers, and patents also provide some data. The carbon footprint was estimated by multiplying the estimated weight of HFA propellant by its GWP. GWP is a measure of how much heat a GHG traps in the atmosphere over a specific time, relative to carbon dioxide. For the purposes of this article, we used GWP values of HFAs for a 100-year time horizon as reported in the Intergovernmental Panel on Climate Change (IPCC) Fifth Assessment Report. ${ }^{17}$

We identified the 20 most commonly prescribed MDIs using NHS prescribing data. ${ }^{18}$ We searched google patents search engine (https://patents.google.com/) using the search terms 'inhaler name' or 'drug name' and HFA or HFA134a or HFA227ea. Links and citations from relevant results were followed. We also reviewed data from the Montreal Protocol Medical Technical Options Committee. ${ }^{19}$

The carbon footprint of commonly prescribed inhalers is summarised in table 2. All salbutamol MDIs use HFA134a, with a GWP of 1300. There are two types of salbutamol MDIs, one a small volume MDI containing alcohol as a co-solvent, which requires less HFA propellant than the large volume alcohol-free type. ${ }^{20} \mathrm{~A}$ study comparing a large volume inhaler Ventolin Evohaler with small volume Salamol inhaler found the weight of the contents (mainly HFA134a propellant) to be 17.32 
Table 2 Indicative carbon footprint of commonly prescribed MDIs by inhaler class

\begin{tabular}{|c|c|c|c|c|c|c|}
\hline $\begin{array}{l}\text { Class of inhaler } \\
\text { (and most } \\
\text { commonly } \\
\text { prescribed } \\
\text { inhaler in this } \\
\text { class) }\end{array}$ & $\begin{array}{l}\text { Indicative } \\
\text { amount } \\
\text { of HFA } \\
\text { propellant per } \\
\text { inhaler }(\mathrm{g})\end{array}$ & $\begin{array}{l}\text { Global } \\
\text { warming } \\
\text { potential of } \\
\text { HFA (over } \\
100 \text { years) } \\
\text { 17 }\end{array}$ & $\begin{array}{l}\text { Carbon footprint } \\
\text { of inhaler }\left(\mathrm{g} \mathrm{CO}_{2} \mathrm{e}\right) \\
\text { (range and midpoint } \\
\text { in brackets) }\end{array}$ & $\begin{array}{l}\text { Actuations } \\
\text { per inhaler }\end{array}$ & $\begin{array}{l}\text { Carbon } \\
\text { footprint per } \\
\text { actuation ( } \mathrm{g} \\
\mathrm{CO}_{2} \mathrm{e} \text { ) }\end{array}$ & Source \\
\hline $\begin{array}{l}\text { Small volume } \\
\text { SABA (eg, } \\
\text { Salamol) }\end{array}$ & $6.68-8.5$ & 1300 & $\begin{array}{l}8680-11050 \\
(9870)\end{array}$ & 200 & $\begin{array}{l}43.4-55.3 \\
(48.6 \text { in } \\
\text { life cycle } \\
\text { analysis }^{7}\end{array}$ & $\begin{array}{l}\text { Published carbon } \\
\text { footprint study }{ }^{9} \text { Inhaler } \\
\text { performance study }{ }^{20} \\
\text { patent }^{49}\end{array}$ \\
\hline $\begin{array}{l}\text { Large volume } \\
\text { SABA (eg, } \\
\text { Ventolin) }\end{array}$ & 17.32-19.8 & 1300 & $\begin{array}{l}22520-28000 \\
(25260)\end{array}$ & 200 & $112-129$ & $\begin{array}{l}\text { Inhaler performance } \\
\text { study, }{ }^{20} \text { patents, } \\
{ }^{21} 22 \\
\text { independently certified } \\
\text { study }^{23}\end{array}$ \\
\hline ICS (eg, Clenil) & $11.32-20$ & 1300 & $\begin{array}{l}14700-26000 \\
(20350)\end{array}$ & 200 & $73.5-130$ & $\begin{array}{l}\text { Patents, }{ }^{24} 25 \\
\text { independently certified } \\
\text { study }^{23}\end{array}$ \\
\hline $\begin{array}{l}\text { HFA134a ICS/ } \\
\text { LABA (eg, Fostair) }\end{array}$ & $12-18.2$ & 1300 & $\begin{array}{l}15600-23700 \\
(19650)\end{array}$ & 120 & $130-197$ & $\begin{array}{l}\text { FDA report, }{ }^{26} \text { patent, }{ }^{21} \\
\text { independently certified } \\
\text { study }^{23}\end{array}$ \\
\hline $\begin{array}{l}\text { HFA 227ea } \\
\text { ICS/LABA (eg, } \\
\text { Flutiform) }\end{array}$ & 11 & 3320 & 36500 & 120 & 295 & Patent $^{27}$ \\
\hline
\end{tabular}

HFA, hydrofluoroalkane; HFA134a, 1,1,1,2-tetrafluoroethane; HFA227ea, 1,1,1,2,3,3,3-heptafluoropropane; ICS, inhaled corticosteroid; LABA, long-acting beta-agonist; MDI, metered-dose inhaler; SABA, short-acting beta-agonist; SAMA, short-acting muscarinic antagonist.

and $7.88 \mathrm{~g}$, respectively. A GlaxoSmithKline (GSK) patent for salbutamol MDI shows inhalers containing $18.2 \mathrm{~g}$ and $19.8 \mathrm{~g}$ of HFA134a. ${ }^{21}{ }^{22}$ GSK published a Carbon Trust-certified carbon footprint analysis which estimated Ventolin to have a carbon footprint of $28 \mathrm{~kg} \mathrm{CO}_{2} \mathrm{e} /$ inhaler, far greater than a small volume inhaler (Proventil) at around $10 \mathrm{kgCO}_{2} \mathrm{e} /$ inhaler. $^{12} 23$

For SAMAs, we used manufacturer's product carbon footprint data on Atrovent which has a product carbon footprint of $14.59 \mathrm{~kg} .{ }^{14}$

For ICS, comparison of two patents for beclometasone inhalers, suggest that those with alcohol use around half the HFA134a propellant (12.3 g with alcohol vs $20 \mathrm{~g}$ of HFA134a alone) of HFA134a. ${ }^{24} 25$

For LABA/ICS combination inhalers, one patent for fluticasone/salmeterol MDI (Seretide) contained $18.2 \mathrm{~g}$ of HFA134a. ${ }^{21}$ GSK published carbon footprint estimates $19 \mathrm{~kg} \mathrm{CO}_{2} \mathrm{e} /$ inhaler for their LABA, ICS/LABA and LABA MDIs. However, an FDA report on the US Advair brand of fluticasone/salmeterol MDI stated the inhaler has a net weight of just $12 \mathrm{~g} /$ inhaler. $^{26}$

Two LABA/ICS MDIs (Symbicort MDI and Flutiform) use HFA227ea as a propellant, which has higher GWP of 3320. A patent for Flutiform indicates it contains $11 \mathrm{~g}$
$( \pm 0.5 \mathrm{~g})$ of HFA227ea, resulting in the largest carbon footprint of any inhaler at $36.5 \mathrm{~kg} \mathrm{CO} \mathrm{e} /$ inhaler. $^{27}$

Currently, both LAMA alone, and LAMA/LABA combinations are exclusively available in the UK as DPIs. There is only one triple ICS/LAMA/LABA combination available in an MDI, and no data on propellant volume could be found (Trimbow).

\section{DPIs and aqueous mist inhalers}

DPIs and aqueous mist inhalers (such as Respimat) do not contain HFAs. The Medical Technical Options Committee of the United Nations estimated the carbon footprint of a DPI to be between 1.5 and $6 \mathrm{~kg} \mathrm{CO}_{2} \mathrm{e}$ for a 200-dose inhaler (7.5-30g/dose) but most DPIs contain far fewer than 200 doses. ${ }^{19}$ GSK's Carbon Trust-verified analysis of their DPIs (containing 1 months' treatment) found a carbon footprint of slightly $<1 \mathrm{~kg} \mathrm{CO}_{2} \mathrm{e} /$ inhaler. $^{23}$ Product carbon footprint analysis of Spiriva Respimat published by the manufacturers found it to have a carbon footprint of $780 \mathrm{~g} \mathrm{CO}_{2} \mathrm{e}$, but potentially lower if refill cartridges are used. ${ }^{14}$ For our analyses we assumed a carbon footprint of $1 \mathrm{~kg} \mathrm{CO}$ e per DPI, and used the midpoint of the range of carbon footprints for each class of MDI. 


\section{Patient and public involvement}

A prior survey conducted in Hertfordshire, UK by one of the authors (AW) found that $86 \%$ of patients agreed that both cost and carbon footprint are important factors to consider when changing inhalers, although ease of use was considered the most important factor overall. ${ }^{28}$

\section{RESULTS}

\section{Financial implications}

By analysing NHS prescription data, we modelled how prescription costs would change in various different prescription scenarios. In model 1, we replaced MDIs with DPIs in the same proportions that brands of DPIs had been prescribed in England 2017, which we called 'proportional replacement'. In this scenario, for every $10 \%$ of MDIs changed the total cost increased by $£ 12.7 \mathrm{M}$ annually. In model 2, we replaced MDIs with the cheapest available equivalent DPI. In this scenario, for every $10 \%$ of MDIs changed total cost decreased by $£ 8.2 \mathrm{M}$ annually, but we saw different price changes for different types of inhalers.

SABA; salbutamol: when salbutamol MDIs were replaced with Salbulin Novolizer costs rose £2.02M for every $10 \%$ of MDIs changed. As Salbulin Novolizer is rarely used in the UK, we modelled an alternative scenario in which we changed MDIs to Salbutamol Easyhaler, whereby costs rose $£ 3.01 \mathrm{M}$ for every $10 \%$ of inhalers changed.

$\angle A B A$ : when switching to Formoterol Easyhaler savings of $£ 1.02 \mathrm{M}$ were made for every $10 \%$ of MDIs changed. For proportional replacement, costs increased by $£ 1.47 \mathrm{M}$ for every $10 \%$ of MDIs changed.

ICS: we found costs increased slightly; £207K for every $10 \%$ of MDIs switched to the cheapest DPI. For proportional replacement costs rose $£ 8.25 \mathrm{M}$ for every $10 \%$ of MDIs changed.

LABA/ICS combination inhalers: we saw large cost savings; $£ 10.0 \mathrm{M}$ saved for every $10 \%$ of MDIs switched to the least expensive DPI LABA/ICS. When switching to Fostair 100/6 Nexthaler instead of Relvar 92/22 Ellipta, as Fostair also has a license for maintenance and reliever therapy, we saw more modest cost savings of $£ 6.25 \mathrm{M}$ for every $10 \%$ of MDIs switched. For 'proportional' replacement costs fell $£ 668 \mathrm{~K}$ for every $10 \%$ of MDIs changed.

LABA/ LAMA/ICS inhalers: in 2017, only 5211 of these inhalers were prescribed and the cost of switching from MDI to DPI was $£ 555 \mathrm{~K}$ for every $10 \%$ of inhalers switched.

\section{Carbon footprint}

We found some reliever inhalers (eg, Ventolin) to have a carbon footprint over $25 \mathrm{~kg} \mathrm{CO}_{2} \mathrm{e}$ per inhaler, while others use far less HFA134a (eg, Salamol) with a carbon footprint of $<10 \mathrm{~kg} \mathrm{CO}_{2}$ e per inhaler. HFA227ea LABA/ ICS inhalers (eg, Flutiform) have a carbon footprint over $36 \mathrm{~kg} \mathrm{CO}_{2} \mathrm{e}$, compared with an equivalent HFA134a combination inhaler (eg, Fostair) at $<20 \mathrm{~kg} \mathrm{CO}_{2}$ e.We estimated the total carbon footprint of MDIs prescribed in the community in England in 2017 to be $635 \mathrm{kt} \mathrm{CO}_{2} \mathrm{e}$. For every $10 \%$ of HFA MDIs changed to low GWP devices 58 kt $\mathrm{CO}_{2} \mathrm{e}$ could be saved annually. Reaching the Environmental Audit Committee target of 50\% of inhalers being low GWP devices by 2022, would save $288 \mathrm{kt} \mathrm{CO}_{2}$ e every year. Reducing the proportion of high GWP devices to $10 \%$, as seen in Sweden, would result in carbon savings 519 kt $\mathrm{CO}_{2}$ e every year.

\section{DISCUSSION}

If prescribers switch from high GWP to the least expensive low GWP options within each therapeutic category, major financial savings could be made alongside large carbon reductions. Most of the savings are seen by switching from more expensive LABA/ICS MDIs to less expensive DPIs. These potential savings would exceed the cost of switching the larger volume of salbutamol MDIs to DPIs, because the incremental cost per salbutamol inhaler $(<£ 2 /$ inhaler $)$ is much lower.

A second option in which prescribers switch from MDI to the DPIs according to the current proportions of brand prescribing, would be more expensive. Neither clinicians nor formularies would likely support a switch to equivalent inhalers which were more expensive. A third option in which prescribers switch from an MDI to DPI for the same branded LABA/ICS combination (eg, Seretide or Fostair) is generally either cost neutral or less expensive.

There is recent focus on cost-effectiveness, which takes into account ease of use, dose frequency and other 'softer' factors that would encourage adherence, impact clinical outcomes and in turn economic cost in the real world. Poor inhaler technique is very common and greatly limits the effectiveness of inhaled medications. The most recent large meta-analysis identified fewer errors overall with DPIs, even when MDI users had spacers. ${ }^{29}$ The Salford lung study was a large, pragmatic randomised trial that showed improved clinical outcomes in patients with asthma and chronic obstructive pulmonary disease assigned to oncedaily Relvar DPI instead of their usual inhaler (which was an MDI in 68\%).${ }^{30}{ }^{31}$ One historical matched cohort study found better asthma control in patients initiated on an MDI compared with DPI, but this study only compared Seretide Evohaler and Accuhaler. ${ }^{32}$ A similar matched cohort study demonstrated patients with asthma can be switched from other ICS inhalers to the Easyhaler with no reduction in clinical effectiveness or change in cost. ${ }^{33}$ Another similar study found better asthma control and fewer exacerbations in patients starting or increasing strength of DPIs or breath-actuated inhalers compared with pMDIs. ${ }^{34} \mathrm{~A}$ further benefit of DPIs is that they use a dose counter, whereas salbutamol and ICS MDIs generally do not. Patients often cannot determine when their MDIs are empty and either throw away half full inhalers, or conversely continue to use empty inhalers unknowingly. ${ }^{35}$

Our cost analysis has a number of limitations. Our data only includes community prescriptions in England; hospital prescriptions are not included. However, patients receiving prescriptions from hospital are likely to have 
more severe disease requiring combination inhalers, so the potential cost savings could be even greater. Our models do not include the impact of future changes in prescribing practice such as the recent introduction of triple LAMA/LABA/ICS inhalers. In reality, costs are in flux and subject to market pressures, but our analysis allows comparison between treatments at a specific time point.

The MDIs assessed were found to have a wide range of carbon footprints; 10-37 times that of a DPI. The UK government reports incorrectly assumes that all inhalers contain $12 \mathrm{~g}$ of propellant. ${ }^{36}$ Even among MDIs, those containing HFA227ea propellant or large volume HFA134a propellant have twice the carbon footprint or more compared with small volume MDIs. At least 6.5 million large volume MDIs for salbutamol were prescribed in England in 2016, and switching these to small volume MDIs could save $118 \mathrm{kt} \mathrm{CO}_{2} \mathrm{e}$ in England alone, with little clinical or patient impact. ${ }^{37}$ Our findings provide a potentially more accurate model that could be transferred to other countries wanting to monitor and regulate MDIs in relation to carbon footprint.

Inhaler recycling has the potential to reduce the environmental impact of inhalers through recovery of propellant, although so far uptake has been very low with $<1 \%$ of MDIs recovered and of little measurable impact in climate terms. ${ }^{13}$ Where recycling is not available, incinerating MDIs with medicines waste is an effective strategy; this causes thermal degradation of the HFA into chemicals with far smaller global warming potential. ${ }^{38}$ A study of inhalers returned for recycling jointly funded by GSK and NHS Grampian showed that $48 \%$ of doses remain in
MDIs, compared with just 27\% in DPIs. ${ }^{39}$ This highlights the importance of explaining to patients the number of doses their inhaler contains as part of inhaler technique training. This also means that a significant proportion of the propellant could be captured, and that the carbon footprint of MDIs potentially roughly halved if they were all recycled and the HFA propellant reused. At the end of their useful life HFA must be incinerated however, and it is possible that recycling HFAs could provide further opportunities for atmospheric release by delaying incineration. Other strategies to reduce GHG emissions from MDIs are summarised in table 3 .

An important question is whether to switch to DPIs now, or wait for reformulated MDIs with novel low GWP propellants. Three low GWP propellants have been considered, isobutane, HFA152a and HFO 1234ea. An isobutane programme has been underway for a decade in Argentina, but not yet been commercialised. HFA152a has a lower carbon footprint (one-tenth of HFA134a) and HFO1234ea zero, but both remain at early stage development. ${ }^{1}$ Very large clinical trials will be required to establish their safety, alone and then in combination with every moiety that uses them. Transition to a novel propellant(s) would likely take at least a decade based on experience from the transition from CFCs, ${ }^{40}$ although this may be cost-effective from a worldwide perspective, especially in low-income and middle-incomedeveloping countries.

Several papers assert that some patients are unable to generate the inspiratory flows necessary to activate DPIs, particularly during exacerbations. ${ }^{41}{ }^{42}$ However, 93\% of prescriptions for LAMA or LAMA/LABA devices for COPD in England are for DPIs, suggesting clinicians believe the

Table 3 Strategies to reduce greenhouse gas emissions from MDIs

\begin{tabular}{lll}
\hline Strategy & Effect & Potential $\mathbf{C O}_{2} \mathbf{e ~ s a v i n g ~}$ \\
\hline $\begin{array}{l}\text { Where appropriate, switch from MDI to } \\
\text { non-propellant inhaler }\end{array}$ & Avoids use of HFA propellants. & 8-36 kg per inhaler. \\
$\begin{array}{lll}\text { Change from large volume reliever } \\
\text { (eg, Ventolin Evohaler) to small volume }\end{array}$ & $\begin{array}{l}\text { Small volume reliever contains far less } \\
\text { propellant. }\end{array}$ & 18 kg per inhaler.
\end{tabular}

reliever (eg, Salamol)

Change from HFA227ea inhaler (eg, $\quad$ Uses lower GWP HFA propellant. $\quad 20 \mathrm{~kg} \mathrm{CO} \mathrm{C}_{2}$ per inhaler.
Flutiform or Symbicort MDI) to HFA134a
inhaler

Recycle used MDls

The plastics and aluminium are recycled Estimated 4-18 kg per inhaler, although and the HFA gas is captured for re-use. potentially risks further atmospheric release of HFA by delaying incineration.

$\begin{array}{lll}\begin{array}{l}\text { Return used inhalers to pharmacy after } \\ \text { use }\end{array} & \begin{array}{l}\text { If the pharmacy cannot recycle the } \\ \text { MDI, it will be incinerated. This causes } \\ \text { thermal degradation of the HFA into } \\ \text { chemicals with far smaller global } \\ \text { warming potential. }\end{array} & \begin{array}{l}\text { Likely to be slightly lower than recycling } \\ \text { due to the energy inputs for incineration, } \\ \text { and the absence of recycled materials. } \\ \text { Estimated } 3-17 \mathrm{~kg} \text { per inhaler. }\end{array} \\ \begin{array}{l}\text { If there is no dose counter, ensure your } \\ \text { patient knows how many doses the } \\ \text { inhaler contains }\end{array} & \begin{array}{l}\text { Reduce waste from disposing of half- } \\ \text { used inhalers. }\end{array} & \begin{array}{l}\text { Estimated to be a quarter of the inhaler's } \\ \text { carbon footprint; roughly } 4 \mathrm{~kg} \mathrm{CO}_{2} \mathrm{e} \text { per } \\ \text { inhaler. }\end{array}\end{array}$

GWP, global warming potential; HFA, hydrofluoroalkane; HFA134a, 1,1,1,2-tetrafluoroethane; HFA227ea, 1,1,1,2,3,3,3-heptafluoropropane; MDI, metered-dose inhaler. 
vast majority of patients can use a DPI effectively. ${ }^{18}$ In contrast, $94 \%$ of SABA prescriptions are for MDIs leading to a confusing mixture of inhalation techniques. ${ }^{18}$ Patients with COPD whose inhaler devices use the same inhalation technique show better clinical outcomes than those prescribed devices requiring different techniques. ${ }^{43}$ One small study examined patients' ability to use MDIs and DPIs effectively during the course of an exacerbation and found best results from an Accuhaler DPI which has medium resistance but is effective at relatively low peak inspiratory flow rates of $30 \mathrm{~L} / \mathrm{min} .{ }^{44}$ Switching to DPI SABAs could potentially lead to a simplification of inhalation technique, an improvement in care and a reduction in carbon footprint. A recent proposal suggests a reliever MDI+spacer could be kept separately in an emergency pack in case of exacerbations. ${ }^{45}$ Whatever inhalers are used, adequate patient training and assessment of inhaler technique will be essential for efficient and effective inhaler use. $^{29}$

Patients care about the carbon footprint of their inhalers. One survey of inhaler users found that $78 \%$ rated carbon footprint as important; equally important to them as financial cost. ${ }^{28}$ Changing one MDI device to a DPI could save $150-400 \mathrm{~kg} \mathrm{CO}_{2}$ e annually; roughly equivalent to installing wall insulation at home, recycling or cutting out meat. ${ }^{46}$ These are individual actions that many environmentally concerned individuals are keen to take.

Our carbon footprint results for England are consistent with other studies of MDIs in the UK (which included Scotland, Wales and Northern Ireland), which show that they contribute approximately a megaton of $\mathrm{CO}_{2} \mathrm{e}$ to global GHG emissions. Climate change is estimated to kill 250000 people annually by 2030 , particularly vulnerable people in financially poor countries. ${ }^{47}$ Physicians should not shy away from these issues, and tools, such as NICE's recent patient decision aid for asthma inhalers are to be welcomed. $^{48}$

\section{CONCLUSIONS}

Climate change is a huge and present threat to health which will disproportionately impact the poorest and most vulnerable on the planet, including people with pre-existing lung disease. Every effort must be made to minimise GHG release to protect current and future generations from the worst effects of climate change.

Switching to low GWP inhalers can be achieved while making financial savings in terms of drug costs. Patients, prescribers and guideline authors should carefully consider the carbon footprint of these inhalers and where they are likely to be equally effective, prioritise low GWP inhalers.

Where MDIs are considered necessary, other steps can be taken immediately to reduce their environmental impact. Smaller volume HFA134a inhalers should be prioritised over larger volume or HFA227ea-containing inhalers, manufacturers should consider phasing out the use of HFA227ea and patients, manufacturers and clinicians should publicise and encourage inhaler recycling.

\section{Twitter Alexander J K Wilkinson @DrAlexWilkinson}

Acknowledgements The authors would like to thank Professor Ashley Woodcock of Manchester University for comments and help refining the manuscript.

Contributors All authors meet the required criteria for authorship. AJKW: helped design the study, collected and analysed the data and wrote the manuscript. RB: helped design the study, collected and analysed the data and revised the manuscript. IS: helped analyse the data and revise the manuscript. JS: helped design the study, collected and analysed the data and revised the manuscript.

Funding The authors have not declared a specific grant for this research from any funding agency in the public, commercial or not-for-profit sectors.

Competing interests JS reports personal fees from Trumpington Street Medical Practice, grants and personal fees from NHS England, personal fees from World Health Organization Europe, Better Value Healthcare, Cambridgeshire County Council, University of Cambridge, outside the submitted work; and he is married to a practising general practitioner in Cambridgeshire.

Patient consent for publication Not required.

Provenance and peer review Not commissioned; externally peer reviewed.

Data availability statement Data are available on reasonable request.

Open access This is an open access article distributed in accordance with the Creative Commons Attribution Non Commercial (CC BY-NC 4.0) license, which permits others to distribute, remix, adapt, build upon this work non-commercially, and license their derivative works on different terms, provided the original work is properly cited, appropriate credit is given, any changes made indicated, and the use is non-commercial. See: http://creativecommons.org/licenses/by-nc/4.0/.

Author note All authors meet the required criteria for authorship: substantial contributions to the conception or design of the work; the acquisition, analysis or interpretation of data for the work; drafting the work or revising it critically for important intellectual content; final approval of the version to be published and agreement to be accountable for all aspects of the work in ensuring that questions related to the accuracy or integrity of any part of the work are appropriately investigated and resolved.

ORCID iD

Alexander J K Wilkinson http://orcid.org/0000-0002-1808-3663

\section{REFERENCES}

1 Myrdal PB, Sheth P, Stein SW. Advances in metered dose inhaler technology: formulation development. AAPS PharmSciTech 2014;15:434-55.

2 NHS Sustainable Development Unit. Reducing the use of natural resources in health and social care. 2018 Report, 2018: 1-31.

3 Lavorini F, Corrigan CJ, Barnes PJ, et al. Retail sales of inhalation devices in European countries: so much for a global policy. Respir Med 2011;105:1099-103.

4 BTS/SIGN British guideline for the management of asthma, SIGN 153, 2016. Available: http://www.sign.ac.uk/sign-153-britishguideline-on-the-management-of-asthma.html

5 Wang $\mathrm{H}$, Horton R. Tackling climate change: the greatest opportunity for global health. Lancet 2015.

6 Hillman T, Mortimer F, Hopkinson NS. Inhaled drugs and global warming: time to shift to dry powder inhalers. BMJ 2013;346.

7 NHS Sustainable Development Unit. Sustainable development in the health and care system: health check 2016. 16, 2016.

8 British Thoracic Society. The environment and lung health position statement, 2017. Available: https://www.brit-thoracic.org.uk/ document-library/audit-and-quality-improvement/environment-andlung-health/the-environment-and-lung-health/

9 Creagh M, Labour MP, Clark C. Conservative MP. Environmental audit Committee UK progress on reducing F-gas emissions, 2018.

10 The NHS long term plan. London, 2019. Available: www. longtermplan.nhs.uk

11 Centre for Sustainable Healthcare. Expert Working Group on reducing the climate change impact of inhalers, 2018. Available: https://networks.sustainablehealthcare.org.uk/networks/sustainablerespiratory-care/expert-working-group-reducing-climate-changeimpact-inhalers [Accessed 24 Jun 2019]. 
12 Goulet B, Olson L, Mayer B. A comparative life cycle assessment between a metered dose inhaler and electric nebulizer. Sustainability 2017;9:1725

13 GSK. Complete the cycle - how we're recycling inhalers, 2018. Available: https://www.gsk.com/en-gb/behind-the-science/howwe-do-business/complete-the-cycle-how-we-re-recycling-inhalers/ [Accessed 18 Jul 2018]

14 Hänsel M, Bambach T, Wachtel H. Reduced environmental impact of a reusable soft mist inhaler. Eur Respir J 2018;52:PA1021.

15 NHS England. NHS digital, 2017. Available: https://digital.nhs.uk/ prescribing [Accessed 17 Jul 2018].

16 Cheyne L, Irvin-Sellers MJ, White J, et al. Tiotropium versus ipratropium bromide for chronic obstructive pulmonary disease. Cochrane Database Syst Rev 2015;23.

17 Global warming potential values, 2014. Available: https://www. ghgprotocol.org/sites/default/files/ghgp/Global-Warming-PotentialValues \%28Feb $162016 \% 29$ 1.pdf [Accessed 17 Jan 2019].

18 NHS Business Services Authority. Available: https://www.nhsbsa. nhs.uk/sites/default/files/2017-10/PCA Aug 17.xlsx \%0A [Accessed 21 Aug 2018].

19 Montreal protocol on substances that deplete the ozone layer report of the UNEP medical technical options Committee 2014 assessment. Nairobi, Kenya, 2014.

20 Sellers WFS. Asthma pressurised metered dose inhaler performance: Propellant effect studies in delivery systems. Allergy Asthma Clin Immunol 2017:13.

21 Akehurst RA, Taylor AJ, Wyatt DA. Aerosol formulations containing Propellant 134a and fluticasone propionate, 1997. Available: https:// www.google.com/patents/US5658549

22 Ian I, Ashurst C, Herman CS, et al. United States Patent (19) 2000.

23 Atherton M. Environmental impact of inhalers, 2017. Available: https://www.greatermanchester-ca.gov.uk/download/meetings/id/ 2423/environmental_impact_of_inhalers [Accessed 27 Aug 2018].

24 Brambilla G, Johnson R, Lewis DA. Aerosol inhalation device, 2014. Available: https://www.google.com/patents/WO2014033057A1?cl= en

25 Brown M, Jones S, Martin G. Metered dose inhalation preparations of therapeutic drugs, 2010. Available: https://patents.google.com/ patent/WO2005055985A1/en?q=qvar+AND+HFA134\&oq=qvar+ AND+HFA134 [Accessed 17 Aug 2018].

26 (DMETS) D of ME and TS. Center for drug evaluation and research application number: NDA 21-254, 2006. Available: https://www. accessdata.fda.gov/drugsatfda_docs/nda/2006/021254s000 NameR.pdf

27 Mueller-Walz R, Fueg LM. Medicinal aerosol formulations, 2014. Available: https://www.google.com/patents/ US20140314684

28 Liew KL, Wilkinson A. P280 How do we choose inhalers? patient and physician perspectives on environmental, financial and ease-of-use factors. Thorax 2017;72:A235-7.

29 Sanchis J, Gich I, Pedersen S, et al. Systematic review of errors in inhaler use: has patient technique improved over time? Chest 2016;150:394-406.

30 Woodcock A, Vestbo J, Bakerly ND, et al. Effectiveness of fluticasone furoate plus vilanterol on asthma control in clinical practice: an open-label, parallel group, randomised controlled trial. Lancet 2017;390:2247-55

31 Vestbo J, Leather D, Diar Bakerly N, et al. Effectiveness of fluticasone Furoate-Vilanterol for COPD in clinical practice. $N$ Engl J Med 2016;375:1253-60.
32 Price D, Roche N, Christian Virchow J, et al. Device type and realworld effectiveness of asthma combination therapy: an observational study. Respir Med 2011;105:1457-66

33 Price DB, Rigazio A, Buatti Small M, et al. Historical cohort study examining comparative effectiveness of albuterol inhalers with and without integrated dose counter for patients with asthma or chronic obstructive pulmonary disease. J Asthma Allergy 2016;9:145-54.

34 Price D, Haughney J, Sims E, et al. Effectiveness of inhaler types for real-world asthma management: retrospective observational study using the GPRD. J Asthma Allergy 2011;4:37-47.

35 Conner JB, Buck PO. Improving asthma management: the case for mandatory inclusion of dose counters on all rescue bronchodilators. J Asthma 2013;50:658-63.

36 Webb N, Broomfield M, Brown P, et al. UK greenhouse gas inventory, 1990 to 2012: annual report for submission under the framework convention on climate change, 2014. Available: https://assets. publishing.service.gov.uk/government/uploads/system/uploads/ attachment_data/file/573172/UKnationalinventoryreport1990-2014. pdf\%0Ahttp://nora.nerc.ac.uk/508171/

37 Williamson IJ, Reid A, Monie RD, et al. Generic inhaled salbutamol versus branded salbutamol. A randomised double-blind study. Postgrad Med J 1997;73:156-8.

38 Waste and Resources Action Programme. Inhalers | recycle now. Available: https://www.recyclenow.com/what-to-do-with/inhalers-0 [Accessed 20 May 2019].

39 NHS Grampian audit. Available: www.dontwasteabreath.com/view/ facts [Accessed 5 Mar 2018].

40 Woodcock $A$. The president speaks: prevention is best: lessons from protecting the ozone layer. Thorax 2012;67:1028-31.

41 Al-Showair RAM, Tarsin WY, Assi KH, et al. Can all patients with COPD use the correct inhalation flow with all inhalers and does training help? Respir Med 2007;101:2395-401.

42 Adachi Y, Adachi YS, Itazawa T. Measurement of peak inspiratory flow rates with an in-check meter to identify preschool children's ability to use dry powder inhalers; Diskus and Turbuhaler. J Allergy Clin Immunol 2004;113.

43 Bosnic-Anticevich S, Chrystyn $\mathrm{H}$, Costello RW, et al. The use of multiple respiratory inhalers requiring different inhalation techniques has an adverse effect on COPD outcomes. Int $J$ Chron Obstruct Pulmon Dis 2017;12:59-71.

44 Broeders MEAC, Molema J, Hop WCJ, et al. The course of inhalation profiles during an exacerbation of obstructive lung disease. Respir Med 2004;98:1173-9.

45 Keeley D, Partridge MR. Emergency MDI and spacer packs for asthma and COPD. Lancet Respir Med 2019;7:380-2.

46 Wynes S, Nicholas KA. The climate mitigation gap: education and government recommendations miss the most effective individual actions. Environ Res Lett 2017;12:074024-9.

47 Climate change and health. World Health Organization, 2018. Available: http://www.who.int/en/news-room/fact-sheets/detail/ climate-change-and-health

48 Excellence $\mathrm{NI}$ for $\mathrm{H}$ and $\mathrm{C}$. Patient decision aid. Inhalers for asthma. London, 2019.

49 Thompson J. A process for the production and screening of materials for use in pharmaceutical aerosol formulations, 2017. Available: https://patents.google.com/patent/EP1588698A2/ [Accessed 4 Aug 2018].

50 Godfrey A, Warby RB. Metered dose inhaler for salmeterol xinafoate, 2003. Available: https://www.google.co.uk/patents/EP1343550A1? $\mathrm{cl}=\mathrm{en}$ 